\title{
Hypertensive Retinopathy as the First Manifestation of Advanced Renal Disease in a Young Patient: Report of a Case
}

\author{
Karen Janeth Arriozola-Rodríguez ${ }^{\mathrm{a}} \quad$ Juan Carlos Serna-Ojeda ${ }^{\mathrm{a}}$ \\ Virginia Alejandra Martínez-Hernández ${ }^{\mathrm{b}}$ José Luis Rodríguez-Loaiza ${ }^{\mathrm{a}}$ \\ ${ }^{a}$ Instituto de Oftalmologia 'Conde de Valenciana', and 'Hospital General de México, \\ Mexico City, Mexico
}

\section{Key Words}

Hypertensive retinopathy $\cdot$ Chronic renal failure $\cdot$ Renal disease $\cdot$ Hypertension

\begin{abstract}
The purpose of this paper was to report the case of a 23-year-old patient suffering from bilateral acute visual loss who received the diagnosis of hypertensive retinopathy. After systemic evaluation, he was diagnosed with bilateral renal disease and chronic renal failure, requiring a kidney transplantation to manage the systemic illness, followed by gradual improvement of his visual acuity.

(C) 2015 The Author(s)

Published by S. Karger AG, Basel
\end{abstract}

\section{Introduction}

Abnormalities in retinal vasculature may reflect similar changes in the blood vessels in other parts of the body, suggesting systemic changes [1], and unlike the complicated invasive procedures that must undergo a patient to assess the cardiac, renal and other tissue's microvasculature, a dilated fundus examination can be performed with a routine screening. These organs share pathophysiological mechanisms, such as endothelial dysfunction and the inflammatory process, leading to circulatory abnormalities and decreased vascular reactivity [2]. In some cases, ophthalmic evaluation may lead to the diagnosis of a life-threatening sys- 
Arriozola-Rodríguez et al.: Hypertensive Retinopathy as the First Manifestation of Advanced Renal Disease in a Young Patient: Report of a Case

temic disorder. Here, we describe the case of a patient in whom the findings of retinal vasculature led to the diagnosis and management of a hypertensive emergency secondary to an advanced chronic renal disease.

\section{Case Report}

A 23-year-old male without previous medical history presented to the emergency department of our institution for evaluation because of sudden and painless vision loss in both eyes of over 1 week without any other systemic complains like headache, dizziness, nausea or vomiting. At evaluation, the best-corrected visual acuity in the right eye was 20/800 and $20 / 400$ in the left eye. Anterior segment examination showed no abnormalities for both eyes. The bilateral intraocular pressure was $16 \mathrm{~mm} \mathrm{Hg}$. At fundoscopy, both eyes showed mild papillary edema, rectified retinal vessels, with loss of the normal retinal-vein relation due to arteriolar narrowing, macular edema, cotton wool spots all over the arcades and involving the peripapillary area, flame-shaped hemorrhages and vascular tortuosity in the retinal periphery (fig. 1a). In the left eye, the presence of lipid exudates with macular star pattern was also relevant (fig. 1b). Fluorescein angiography was evident for vascular tortuosity and hyperfluorescent areas with late leakage in the temporal and peripapillary areas in both eyes (fig. 2a, b), and the right eye showed capillary closure in the foveal avascular zone (fig. 2a). No optical coherence tomography was required at this moment of the evaluation. On systemic evaluation, the patient had an arterial blood pressure of 220/140 mm Hg confirmed on several occasions. Considering the diagnosis of secondary hypertension due to the age of the patient, he was referred for a multidisciplinary approach, not requiring any ophthalmic therapy at this moment. The laboratory tests are shown in table 1 , while other examinations including liver function tests, coagulation tests and serum electrolytes were within normal limits.

A renal ultrasound showed smaller than normal kidneys, the right kidney had dimensions of $65 \times 35 \times 50 \mathrm{~mm}$ (normal size $100 \times 50 \times 30 \mathrm{~mm}$ ), with loss of corticomedullary differentiation and increased echogenicity. The left kidney had dimensions of $66 \times 40 \times 42$ $\mathrm{mm}$, with poorly defined edges, with loss of corticomedullary differentiation and increased echogenicity (fig. 3). A renal biopsy showed glomeruli with open capillary loops and normal basement membranes, a well-preserved interstitium without fibrosis nor tubular atrophy, preglomerular interstitial arteriolar vessels with nodular hyaline wall thickening, and mild reduction of lumen. The diagnosis of chronic renal failure was made, and the patient underwent kidney transplantation from a living related donor. The visual acuity of the patient gradually improved to a best-corrected visual acuity of 20/50 in both eyes after normalization of the blood pressure.

\section{Discussion}

Hypertension is a disease that affects more than 1 billion of individuals throughout the world and is one of the leading causes of death [3]. Up to $1 \%$ of all patients present hypertensive crises, which can be divided into hypertensive urgency if the condition is characterized only by increase of tensional levels, or hypertensive emergency, the latter being a situation that requires immediate reduction of blood pressure because of acute or progressive end-organ damage [3]. In adolescents and young adults with a hypertensive crisis, a secondary cause of hypertension must be suspected, and among them, renovascular disease is one 
Arriozola-Rodríguez et al.: Hypertensive Retinopathy as the First Manifestation of Advanced Renal Disease in a Young Patient: Report of a Case

of the most frequent causes, accounting from 0.2 to $32 \%$ of cases. Other causes of secondary hypertension must also be considered such as antiphospholipid syndrome, aldosteronism or pheochromocytoma [3]. It has been found that $32 \%$ of the patients with hypertension and nephropathy have hypertensive retinopathy because the altered regulatory mechanism appears as thinning of the retinal arterioles and sclerosis that can lead to occlusion and microinfarcts clinically observed as cotton wool spots [4]. The generalized arteriolar narrowing reflects persistent arteriolar damage secondary to long-standing hypertension, and the hemorrhages, microaneurysms and cotton wool spots are related to acute blood pressure elevation [5]. Our patient presented with visual loss and bilateral findings on examination that made us suspect systemic diseases, and the blood pressure lead us to vascular pathologies. This case is similar to other previously reported cases in which retinal abnormalities in young patients suggested a systemic condition [3].

Hypertensive retinopathy can cause a spectrum of clinical manifestations ranging from arteriolar narrowing to papilledema. This patient was classified as grade 3 retinopathy according to the Keith-Wagener-Barker classification system and as grade 3 according to the Scheie classification [6]. Malignant hypertension presents with fibrinoid necrosis of afferent arterioles and focal glomeruli necrosis [7]. In secondary malignant hypertension, choroidopathy, retinal pigment epithelial lesions and serous retinal detachment can be detected on fundoscopy [8]. The most important markers of damage are micro- or macroalbuminuria, which were present in our patient. Treatment of a hypertensive crisis consists in the immediate control of blood pressure to prevent further end-organ damage [3]. Renal atrophy secondary to chronic renal failure leads to the definitive treatment of renal replacement because the medical management alone does not provide long-term systemic control.

The comprehensive management of patients with suggestive ophthalmic findings is important because many of them can represent initial manifestations of systemic diseases and besides causing loss of vision may threaten the patient's life; this case highlights the importance of a correlation of the ophthalmologic manifestations with systemic abnormalities as well as to make appropriate and multidisciplinary approaches.

\section{Statement of Ethics}

This article does not contain clinical studies or patient data.

\section{Disclosure Statement}

The authors declare that they have no conflicts of interest.

\section{References}

1 Grunwald JE, Alexander J, Ying GS, et al: Retinopathy and chronic kidney disease in the Chronic Renal Insufficiency Cohort (CRIC) study. Arch Ophthalmol 2012;130:1136-1144.

-2 Grunwald JE, Ying GS, Maguire M, et al: Association between retinopathy and cardiovascular disease in patients with chronic kidney disease (from the Chronic Renal Insufficiency Cohort [CRIC] Study). Am J Cardiol 2012;110:246-253.

-3 Wijaya I, Siregar P: Hypertensive crises in the adolescent: evaluation of suspected renovascular hypertension. Acta Med Indones 2013;45:49-54.

4 Malhotra SK, Gupta R, Sood S, et al: Bilateral renal artery stenosis presenting as hypertensive retinopathy and choroidopathy. Indian J Ophthalmol 2002;50:221-223. 
Case Reports in

Ophthalmology

\begin{tabular}{l|l}
\hline Case Rep Ophthalmol 2015;6:415-419 \\
\hline DOI: 10.1159/000442660 & $\begin{array}{l}\text { (c) 2015 The Author(s). Published by S. Karger AG, Basel } \\
\text { www.karger.com/cop }\end{array}$ \\
\hline
\end{tabular}
www.karger.com/cop

Arriozola-Rodríguez et al.: Hypertensive Retinopathy as the First Manifestation of Advanced Renal Disease in a Young Patient: Report of a Case

5 Wong TY, McIntosh R: Systemic associations of retinal microvascular signs: a review of recent populationbased studies. Ophthalmic Physiol Opt 2005;25:195-204.

$\checkmark 6$ Chatterjee S, Chattopadhyay S, Hope-Ross M, et al: Hypertension and the eye: changing perspectives. J Hum Hypertens 2002;16:667-675.

7 Choe JY, Park SH, Kim JY, et al: A case of systemic lupus erythematosus presenting as malignant hypertension with hypertensive retinopathy. Korean J Intern Med 2010;25:341-344.

8 Hayreh SS, Servais GE, Virdi PS: Fundus lesions in malignant hypertension. VI. Hypertensive choroidopathy. Ophthalmology 1986;93:1383-1400.

Table 1. Laboratory test results

\begin{tabular}{lll}
\hline & Patient value & Normal value (ranges) \\
\hline Hemoglobin, $\mathrm{g} / \mathrm{dl}$ & 11.6 & $14-18$ \\
Hematocrit, $\%$ & 33.8 & $42-52$ \\
Platelets, $\times 10^{3} / \mu \mathrm{l}$ & 560,000 & $150,000-450,000$ \\
Leukocytes, $\times 10^{3} / \mu \mathrm{l}$ & 4.0 & $4.5-11.0$ \\
Albumin, $\mathrm{mg} / \mathrm{dl}$ & 4.12 & $3.5-5.0$ \\
Creatinine, $\mathrm{mg} / \mathrm{dl}$ & 9.0 & $0.7-1.3$ \\
Cholesterol, $\mathrm{mg} / \mathrm{dl}$ & 219 & $140-200$ \\
Triglycerides, $\mathrm{mg} / \mathrm{dl}$ & 304 & $45-179$ \\
Urinalysis, $\mathrm{mg} / \mathrm{dl}$ & & \\
$\quad$ Protein & 600 & negative \\
$\quad$ Glucose & 30 & negative \\
\hline
\end{tabular}
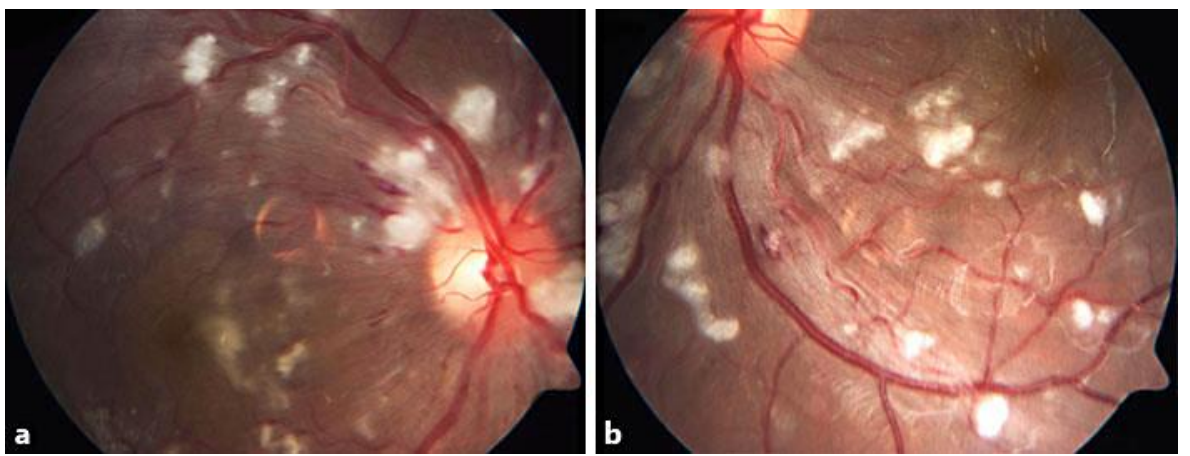

Fig. 1. a Right eye fundoscopy showing cotton wool spots following the path of the arcades, vascular tortuosity and flame-shaped hemorrhages. $\mathbf{b}$ Lower region of the posterior pole of the left eye showing a macular star pattern. 


\section{Case Reports in \\ Ophthalmology}

\begin{tabular}{l|l}
\hline Case Rep Ophthalmol 2015;6:415-419 \\
\hline DOI: $10.1159 / 000442660$ & $\begin{array}{l}\text { (c) } 2015 \text { The Author(s). Published by S. Karger AG, Basel } \\
\text { www.karger.com/cop }\end{array}$ \\
\hline
\end{tabular}

Arriozola-Rodríguez et al.: Hypertensive Retinopathy as the First Manifestation of Advanced Renal Disease in a Young Patient: Report of a Case
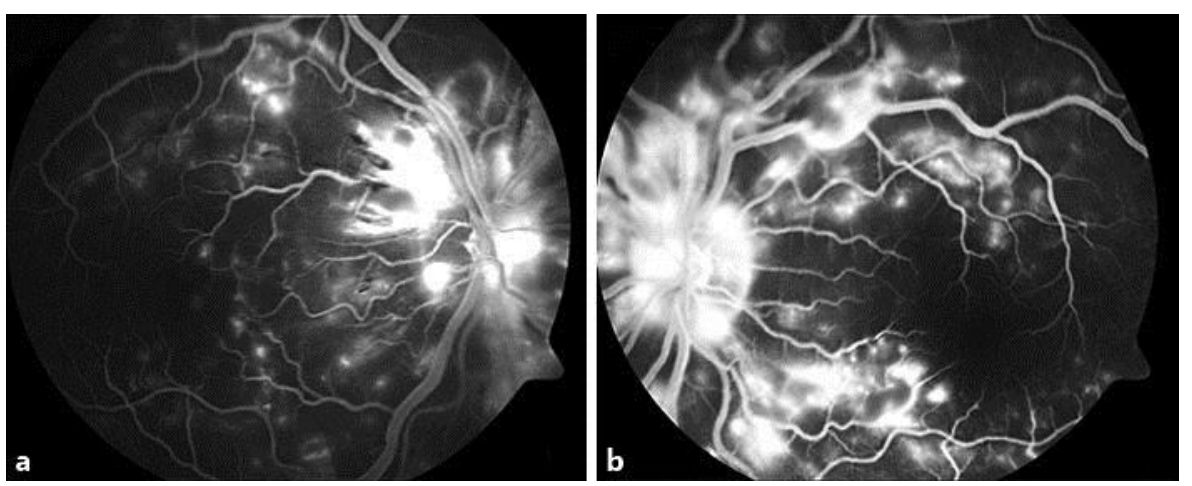

Fig. 2. a Fluorescein angiogram in the late arteriovenous phase showing papillary hyperfluorescence. b Fluorescein angiogram of the left eye in the venous phase showing peripapillary hyperfluorescence.

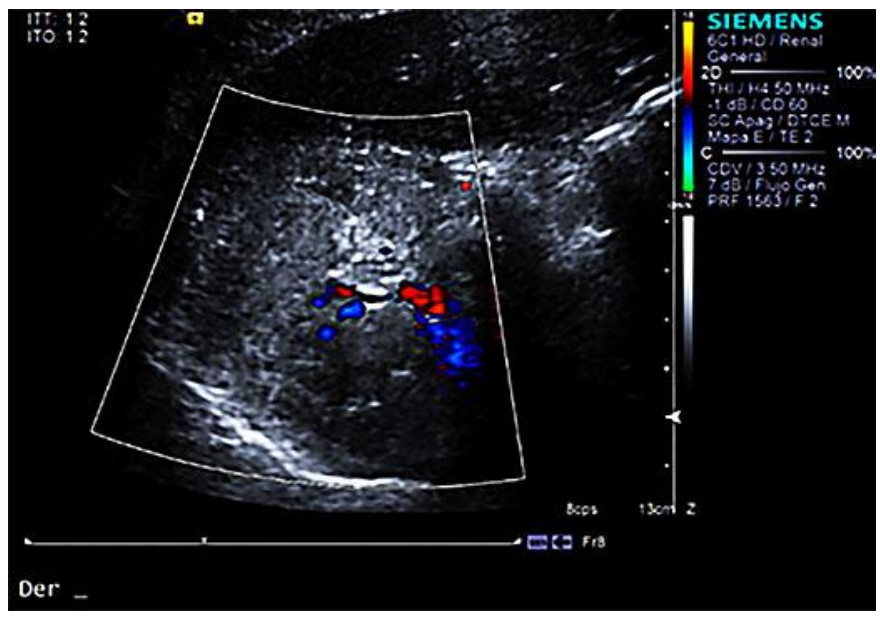

Fig. 3. Renal ultrasound showing decrease in renal size with diffuse increased echogenicity and loss of corticomedullary differentiation. Global decrease in vascularity is evident after Doppler. 